\title{
Optical properties, physiologic parameters and tissue composition of the human uterine cervix as a function of hormonal status
}

\author{
Bettina Matzinger • Martin Wolf • Ana Baños • \\ Daniel Fink • René Hornung
}

Received: 6 June 2008 / Accepted: 19 August 2008 / Published online: 28 November 2008

(C) Springer-Verlag London Limited 2008

\begin{abstract}
The influence of sex hormones on the human uterine cervix is likely to be important in the process of cervical ripening. Frequency domain near-infrared spectroscopy (FD-NIRS) was used to investigate non-invasively the changes in the optical properties that reflect physiologic parameters and tissue composition of the uterine cervix in the different phases of the menstrual cycle. Twenty premenopausal and nine postmenopausal women were examined. Optical properties of the uterine cervix were measured, and physiological parameters [concentration of water, oxyhemoglobin $\left(\mathrm{O}_{2} \mathrm{Hb}\right)$ and deoxyhemoglobin $(\mathrm{HHb})$, total hemoglobin $(\mathrm{tHb})$, oxygen saturation $\left(\mathrm{StO}_{2}\right)$, water, and scattering power] were calculated. Analysis of variance (ANOVA) was used to test for statistical significance. The optical properties of the anterior cervical lip did not differ from those of the posterior lip. HHb was significantly lower in cervices during menstrual bleeding than during the follicular, luteal, or
\end{abstract}

B. Matzinger $\cdot$ A. Baños $\cdot$ D. Fink

Department of Obstetrics and Gynecology,

University Hospital of Zürich,

Zürich, Switzerland

\section{Wolf}

Biomedical Optics Research Laboratory, Clinic of Neonatology University Hospital Zurich,

Zürich, Switzerland

\section{R. Hornung}

Department of Obstetrics and Gynecology,

Kantonsspital,

St. Gallen, Switzerland

\section{B. Matzinger $(\square)$}

Frauenklinik Maternité, Stadtspital Triemli,

Birmensdorferstrasse 501,

8063 Zürich, Switzerland

e-mail: bmatzinger@gmx.net postmenopausal phases. The ratio of $\mathrm{O}_{2} \mathrm{Hb}$ to $\mathrm{HHb}$ was highly significantly increased by a factor of 2 when cervices during the menstrual bleeding were compared with those during the follicular, luteal, or postmenopausal phases. The scattering power was significantly lower during menstrual bleeding than during the follicular or postmenopausal phases. We demonstrated that withdrawal of sex hormones during menstrual bleeding is associated with a significant decrease in $\mathrm{HHb}$ and scattering power, with stable values of $\mathrm{O}_{2} \mathrm{Hb}$, $\mathrm{tHb}, \mathrm{StO}_{2}$, and $\mathrm{H}_{2} \mathrm{O}$ compared with the values during the follicular, luteal or postmenopausal phases of the menstrual cycle. Cervical softening during menstrual bleeding seems to be different from cervical softening for labor.

Keywords Uterine cervix - Cervical ripening .

Frequency domain near-infrared spectroscopy (FD-NIRS) .

Optical properties of the human uterine cervix .

Hormonal status

\section{Introduction}

Preterm labor is responsible for $70 \%$ of perinatal deaths and nearly half of long-term neurological morbidity [1], and it is probably one of the most challenging problems in modern obstetrics and gynecology. One of the keys to treating preterm labor and preventing severe neonatal complications could be the early identification of women at risk. Evaluation of cervical ripening to predict preterm labor is commonly performed by digital examination or sonography.

Preterm cervical ripening may be induced by local infection, cervical incompetence or uterine contractions. Undoubtedly, cervical ripening is associated with many biochemical and physiological changes of the cervical tissue. Hormone-regulated biochemical changes occur 
during pregnancy, ultimately leading to cervical ripening and birth [2]. We recently demonstrated that prostaglandininduced cervical ripening results in a significant change in optical properties (i.e., the absorption and scattering of light), a significant decrease in total hemoglobin ( $\mathrm{tHb}$ ), oxyhemoglobin $\left(\mathrm{O}_{2} \mathrm{Hb}\right)$, deoxyhemoglobin $(\mathrm{HHb})$, and a highly significant increase in water content $\left(\mathrm{H}_{2} \mathrm{O}\right)$ [3]. So far, the influence of sex hormones on the optical properties of the human uterine cervix has not been investigated, but it is likely to be important in the process of cervical ripening [4].

Near-infrared spectroscopy (NIRS) is used to characterize the optical properties of thick tissues in vivo in a noninvasive way [5]. Optical properties can be quantitatively defined in terms of the absorption and reduced scattering coefficients $\left(\mu_{\mathrm{a}}\right.$ and $\left.\mu_{\mathrm{s}}^{\prime}\right)$ of light. These parameters are sensitive to tissue concentrations of light-absorbing molecules and light scattering structures. The primary tissue contributors to light absorption are $\mathrm{O}_{2} \mathrm{Hb}, \mathrm{HHb}, \mathrm{H}_{2} \mathrm{O}$ ), lipids, cytochromes and melanin [6]. Light scatterers are the structural elements of tissue, such as cell components and fibrous materials in the extracellular matrix (e.g., collagen/ elastin). Frequency domain NIRS (FD-NIRS) is a technique capable of quantifying absolute tissue $\mu_{\mathrm{a}}$ and $\mu_{\text {s }}$ values. Absolute concentrations of tissue $\mathrm{O}_{2} \mathrm{Hb}, \mathrm{HHb}, \mathrm{tHb}$, oxygensaturation $\left(\mathrm{StO}_{2}\right)$ and $\mathrm{H}_{2} \mathrm{O}$ are derived from the $\mu_{\mathrm{a}}$ of the tissue $[7,8]$. We used FD-NIRS to examine in vivo the optical properties of human cervical tissues in various menstrual phases. Postmenopausal woman with low levels of estrogen and progesterone were compared with premenopausal woman during the three phases of the menstrual cycle, namely menstruation, the follicular phase, with high levels of estrogen, and the luteal phase, with high levels of estrogen and progesterone.

The aim of this study was to investigate the optical properties and tissue composition of the human uterine cervix during the above-mentioned menstrual phases to elucidate the effects of the sex steroid hormones on cervical ripening in non-pregnant women.

\section{Patients, materials and methods}

A total of 29 women scheduled for hysterectomy were included in the study after we had obtained their written informed consent. Four woman were menstruating (i.e., days 1-4 of the menstrual cycle), seven woman were in the follicular phase (i.e., day 5-14 of the menstrual cycle), nine woman were in the luteal phase (i.e., days 16-28 of the menstrual cycle), and nine woman were postmenopausal.

In the operating theater during anesthesia, immediately prior to surgery, a routine gynecological examination was performed by an experienced gynecologist. The vaginal probe was sterilized according to hospital standards for clinical instruments. At the end of the routine clinical checkup, while the gynecological speculum was still in situ, the uterine cervix was cleaned to remove mucous and detritus in order to allow optimal light penetration and signal detection. The vaginal probe of the FD-NIRS instrument was inserted into the vagina and placed on the vaginal portion of the uterine cervix with gentle pressure, ensuring good probe-to-cervix contact but without altering perfusion. Measurements were taken once on each quadrant of the cervix. The data acquisition time was approximately 30 s per measurement; thus, the overall examination time for the study was no more than 2 min per patient, leading to negligible additional discomfort for the patient. The probe was withdrawn from the vagina. The data acquisition technique is standardized, and has been performed by the same physician for all patients, ensuring high precision.

The FD-NIRS instrument used at the Department of Obstetrics and Gynecology, University Hospital of Zurich, is a modified Imagent (ISS, Champaign, IL, USA). It is equipped with seven near-infrared diode lasers (emitting at $690 \mathrm{~nm}, 730 \mathrm{~nm}, 750 \mathrm{~nm}, 808 \mathrm{~nm}, 870 \mathrm{~nm}, 920 \mathrm{~nm}$ and $970 \mathrm{~nm}$ ) and one avalanche photodiode light detector. The instrument includes a pair of frequency synthesizers (PTS 500 frequency synthesizer, Programmed Test Sources Inc., Littleton, USA) capable of switching frequencies within less than $1 \mathrm{~ms}$. One frequency synthesizer modulates the intensity of the laser diodes with frequencies between $130 \mathrm{MHz}$ and $490 \mathrm{MHz}$, while the other modulates the detector at a frequency which is $5 \mathrm{kHz}$ different from the source modulation, thus demodulating the light frequency at the detector. The instrument is equipped with a complete software package (Boxy, ISS) for data acquisition and two calibration blocks with known optical properties. Once data acquisition has been initiated, the frequency dependence of the phase and amplitude of the photon density wave is measured in steps of $10 \mathrm{MHz}$ and fit to analytically derived model functions in order to calculate $\mu_{\mathrm{a}}$ and $\mu_{\mathrm{s}}$ parameters for each wavelength. In addition, the wavelength dependence of absorption is automatically used to calculate $\mathrm{O}_{2} \mathrm{Hb}, \mathrm{HHb}, \mathrm{tHb}, \mathrm{StO}_{2}$ and $\mathrm{H}_{2} \mathrm{O}$. The wavelength-dependent decrease of scattering (scatter power) is calculated by an exponential fit. The system is fully automated.

For our study we utilized the previously described probe, specifically designed for measurements of the human uterine cervix [3]. The vaginal probe was slightly bent, allowing good visualization during placement on the cervix. Eight multimode silica fibers $(400 \mu \mathrm{m}$ diameter, $3 \mathrm{M}$ FT 400 EMT, Thorlabs Inc., USA) were coupled to the laser source to transmit the light to the tip of the probe. One glass fiber bundle ( $3 \mathrm{~mm}$ in diameter) conducted the light from the tip of the probe to the detector. The source-detector separation was $10 \mathrm{~mm}$. Condom-like latex-covers were used to prevent transfection from patient to patient. 
The software package STATISTICA 7.0 (Statsoft Inc., Tulsa, USA.) was used for statistical analysis. All statistical procedures were applied to untransformed data. The Kolmogorov-Smirnov test was used to check data for normal distribution. None of the response variables differed significantly from a normal distribution (all $P>0.2$ ). Oneway, two tailed, analysis of variance (ANOVA) was used to calculate statistical significance of differences between optical properties of the uterine cervices grouped into the four menstrual stages $(\mathrm{m}=$ menstruation, $\mathrm{f}=$ follicular, $\mathrm{l}=$ luteal phases, $\mathrm{p}=$ postmenopause). $P$ levels below 0.05 were considered as statistically significant, and those below 0.005 as highly significant.

\section{Results}

The optical properties of the anterior cervical lip did not differ from those of the posterior lip (data not shown). Figure 1 shows $\mathrm{HHb}$ as a function of the four menstrual stages. It was significantly lower in cervices during menstrual bleeding than during the follicular or the luteal phase $(P=0.016, P=0.038)$. A substantial, but not significant, increased level of $\mathrm{O}_{2} \mathrm{Hb}$ was measured in cervices during the menstrual cycle, as shown in Fig. 2. Similarly, $\mathrm{tHb}$ was highest during menstrual bleeding and lowest in postmenopausal cervices (Fig. 3). However, the differences were not significant. The ratio $\mathrm{O}_{2} \mathrm{Hb} / \mathrm{HHb}$ was highly significantly increased by a factor of 2 when cervices during menstrual bleeding were compared with those during the follicular, luteal or postmenopausal phases. Pair-wise comparisons demonstrated that the menstrual

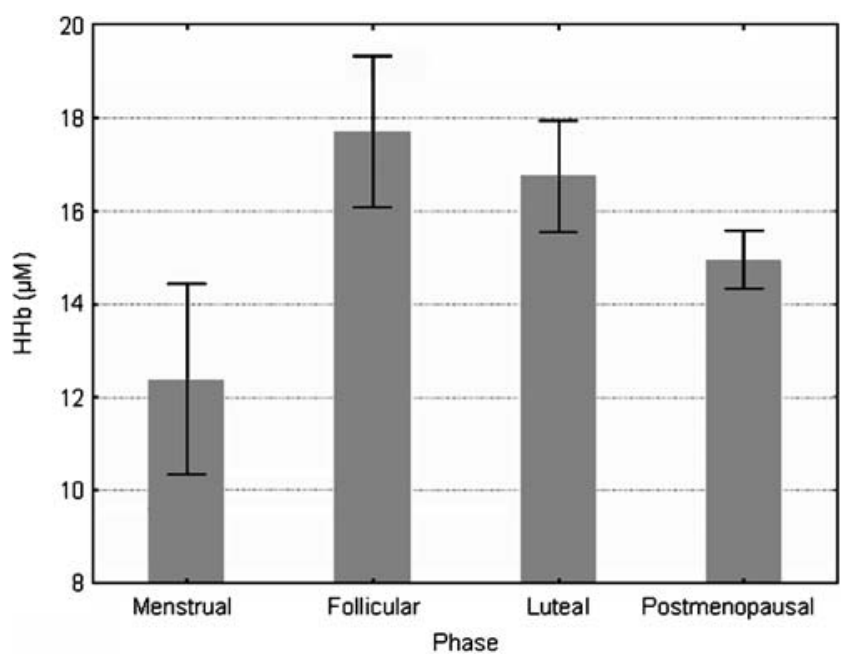

Fig. 1 Deoxyhemoglobin $(\mathrm{HHb})$ is shown as a function of the four menstrual stages. Deoxygenated hemoglobin was significantly lower in cervices during menstrual bleeding than during the follicular or luteal phases, or during the postmenopause phase. Error bars represent the standard deviation

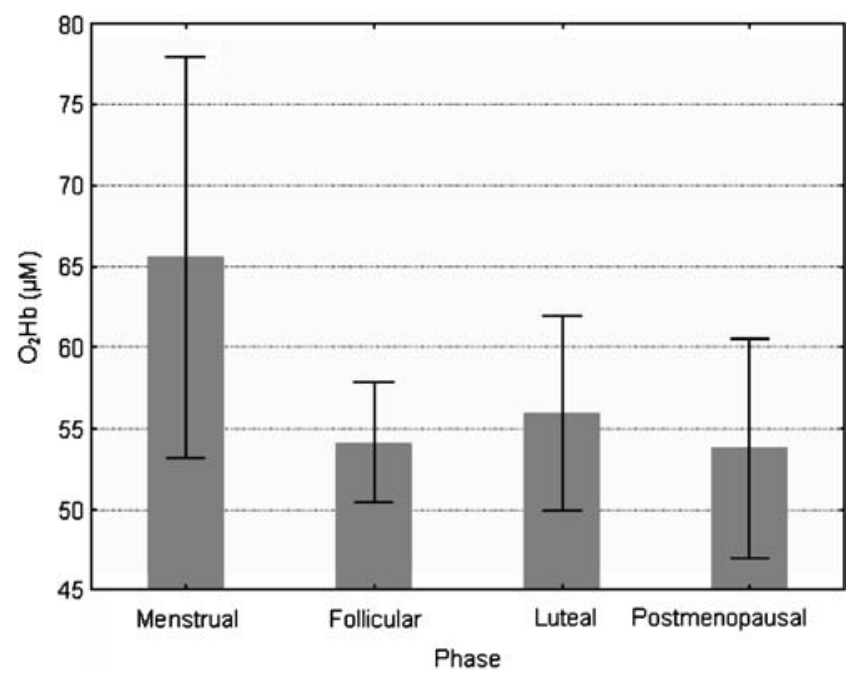

Fig. 2 Oxyhemoglobin $\left(\mathrm{O}_{2} \mathrm{Hb}\right)$ is shown as a function of the four menstrual stages. A substantial, but not significant, increased level of $\mathrm{O}_{2} \mathrm{Hb}$ was measured in cervices during the menstrual cycle. Error bars represent the standard deviation

phase differed significantly from all other phases $(P=$ 0.004, $P=0.003, P=0.005$ for follicular, luteal and postmenopausal phases, respectively). Likewise, oxygen saturation $\left(\mathrm{StO}_{2}\right)$ was markedly increased during menstrual bleeding (Fig. 4). However, the differences when $\mathrm{StO}_{2}$ values during menstruation were compared with those during the other physiological phases were not significant. No differences in tissue water content were observed when cervices were grouped into the four menstrual phases (Fig. 5).

The scattering power (SP; Fig. 6) as a function of the four menstrual phases was significantly lower during menstrual bleeding than during the follicular or postmenopausal

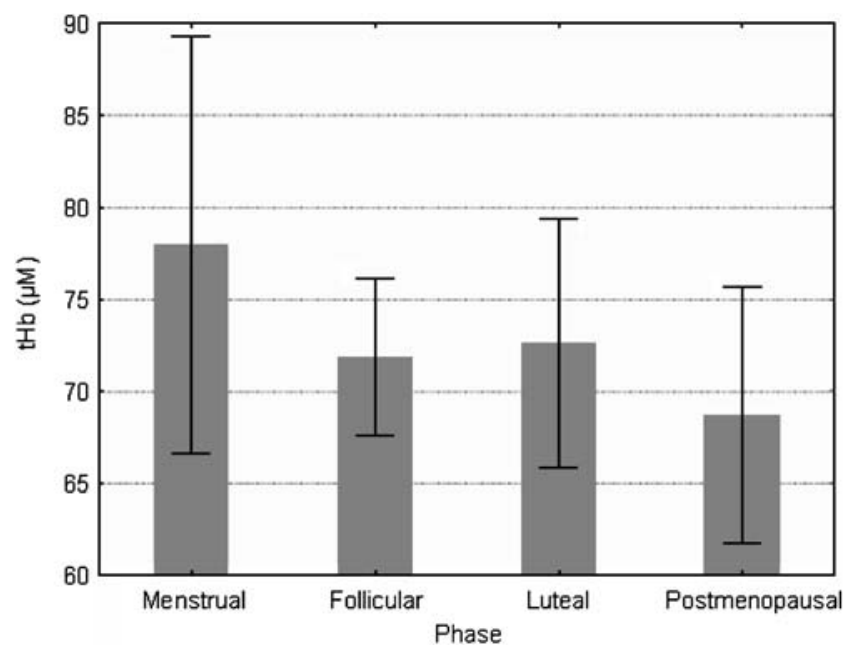

Fig. 3 Total hemoglobin $(\mathrm{tHb})$ is shown as a function of the four menstrual stages. tHb was highest during menstrual bleeding and lowest in postmenopausal cervices. Error bars represent the standard deviation 


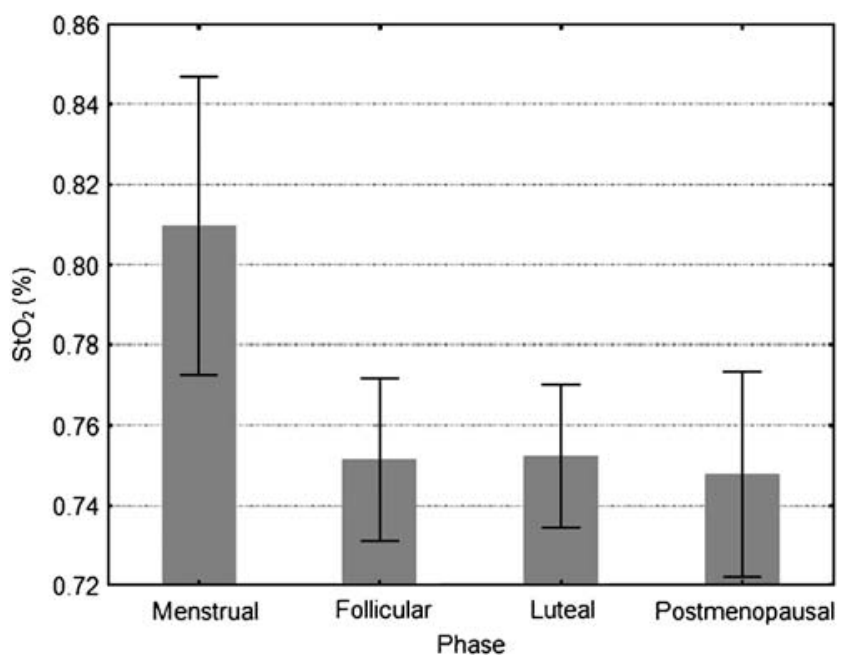

Fig. 4 Oxygen saturation $\left(\mathrm{StO}_{2}\right)$ is shown as a function of the four menstrual stages. $\mathrm{StO}_{2}$ was markedly increased during menstrual bleeding. Error bars represent the standard deviation

phases, but not when compared with the luteal phase $(P=$ $0.043 ; P=0.039 ; P=0.15)$.

\section{Discussion}

Preterm labor is a major obstetric problem, with a potentially adverse fetal outcome. Early identification of women at risk is one the most important aims in the daily routine of every obstetrician. Women at risk are identified on the basis of their history, their microbiological and serological test results, and on the evaluation of their uterine cervices. Bimanual examination and transvaginal sonography of the uterine cervix provide information on

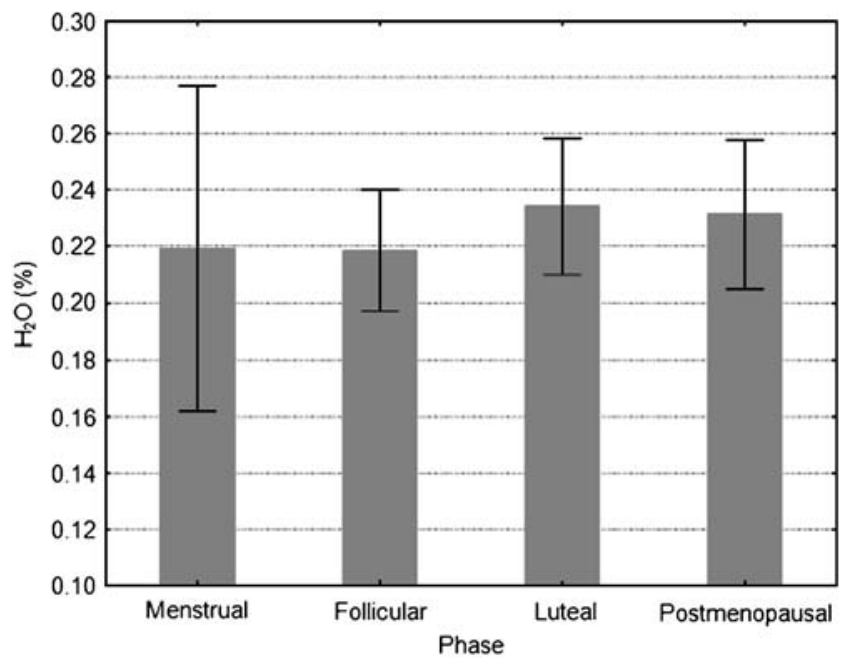

Fig. 5 Tissue water content $\left(\mathrm{H}_{2} \mathrm{O}\right)$ in percent is shown as a function of the four menstrual stages. $\mathrm{H}_{2} \mathrm{O}$ was stable throughout the cycle. Error bars represent the standard deviation

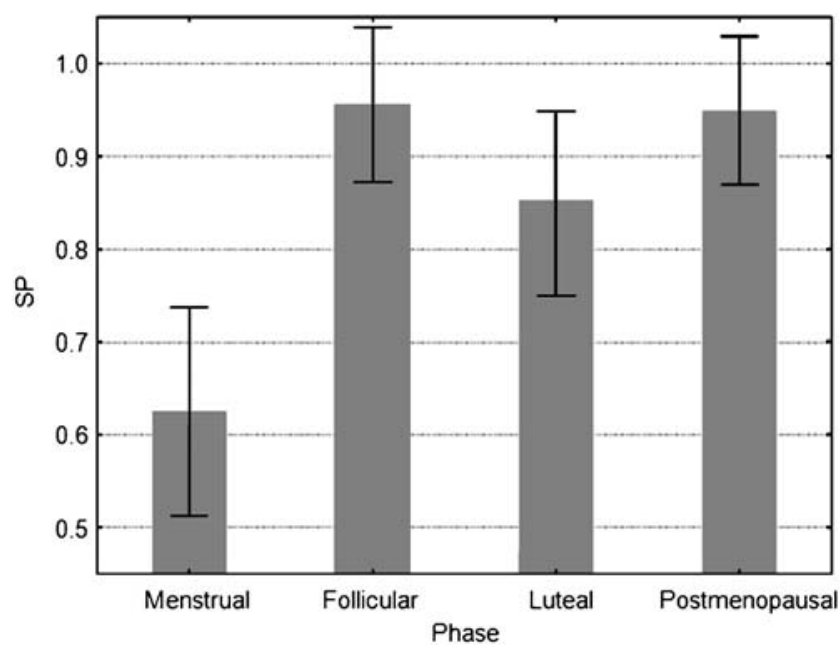

Fig. 6 The scatter power (SP) is shown as a function of the four menstrual phases. SP was significantly lower during menstrual bleeding than during the follicular or postmenopausal phases. Error bars represent the standard deviation

morphology that developed before. The assessment of physiologic profiles predicting preterm delivery is difficult and, so far, very unsatisfactory. Tocography and electromyography can be utilized to monitor contractions of the uterine muscle [9]. The development of new techniques that measure physiologic parameters of the uterine cervix with the potential to predict preterm delivery is of the utmost clinical importance.

In a complex research project we are currently investigating various influences affecting the physiology of the uterine cervix. Among these influences, the effects of hormones on the supply of blood, oxygen and water in the cervix is an important focus [4]. We recently demonstrated that FD-NIRS technology is highly sensitive and accurate in detecting changes in cervical physiology [3, 10]. This is in good agreement with our study, where the comparison of data of the anterior and posterior cervical lips as an internal quality control did not show any differences. In addition, in previous work, we demonstrated that prostaglandin-induced cervical ripening results in a significant change of optical properties, a significant decrease in $\mathrm{tHb}, \mathrm{O}_{2} \mathrm{Hb}$, and $\mathrm{HHb}$, and a highly significant increase in water content [3]. The influence of sex hormones on the optical properties of the uterine cervix and its physiology in non-pregnant individuals is the focus of the study described here.

As shown in Fig. 1, HHb is significantly lower in cervices during menstrual bleeding than during other menstrual phases. $\mathrm{O}_{2} \mathrm{Hb}$, tHb, $\mathrm{StO}_{2}$, and $\mathrm{H}_{2} \mathrm{O}$ showed slight changes throughout the cycle. Interestingly, however, the ratio of $\mathrm{O}_{2} \mathrm{Hb}$ to $\mathrm{HHb}$ was highly significant lower during the menstrual bleeding than during any other phases evaluated. Proliferative processes during the follicular 
phase, i.e., estrogen-dominated phases, and secretory processes during the luteal phase, i.e., the progesteronedominated phases, seem to metabolize substantially more oxygen than during the menstrual phase. In addition, menstrual bleeding is characterized by a strong increase of blood flow into the uterus and its cervix. The blood, however, does not stay in the uterine and cervical tissues but leaves the uterus and is known as menstrual bleeding. Thus, the increased blood influx into the uterine tissue is counterbalanced, in part, by the menstrual bleeding, which is well represented by the $\mathrm{tHb}$ that increased only slightly during the menstrual bleeding (Fig. 3).

The human uterine cervix is a complex tissue. The cervix is composed of an extracellular matrix and cellular components. The extracellular matrix consists predominantly of collagen, elastin and proteoglycans. The cell components consist of smooth muscle cells, fibroblasts, epithelial cells, and blood vessels [11]. The scattering of light is a boundary phenomenon. Boundaries in biologic matters are cell membranes, organelles, or extracellular matrix fibers (i.e., collagen and elastin). As photons propagate in tissues and hit boundaries, the change in refractive index alters the photons' angles of direction, the so-called scattering of light. The scatter power depends on the size distribution of the intra- and extracellular scatterers, which change during apoptosis and extracellular matrix remodeling. In our measurements we observed a significant decrease in scattering power during menstruation. This may be explained by shrinkage of the cell components of the uterine cervix after programmed cell death, so-called apoptosis $[12,13]$. The concept of apoptosis with reduced oxygen consumption by the cells during menstrual bleeding is also supported by the highly significant increase in the ratio of $\mathrm{O}_{2} \mathrm{Hb}$ to $\mathrm{HHb}$ during menstrual bleeding. On the other hand, oxygen saturation remained almost stable during menstrual bleeding. Although it can be assumed that inflammatory processes resulted in increased oxygen consumption by the tissue, this seems to be counterbalanced, in part, by the reduced oxygen requirement of the tissues undergoing apoptosis. The decrease in the scattering power may also be explained by changes in collagen ultrastructure. In naturally cycling mice, circulating estradiol was positively correlated with stromal cell proliferation and collagen type-I content, while it was negatively correlated with loss of collagen type-IV surrounding glandular epithelium and apoptosis in luminal, glandular, and stromal compartments [14]. This may explain why, during the follicular and luteal phases in our study, the scattering power remained at a high level and dropped by one-third during menstrual bleeding. While the high estrogen and progesterone levels during the follicular and luteal phases inhibit collagenase activity $[15,16]$, the decrease in the sex steroid hormones during menstrual bleeding results in increased collagenase activity, with increased collagen fragmentation leading to reduced light scattering and a drop in scattering power (Fig. 6). Similarly, when a mifepristone-induced progesterone withdrawal was induced in the rat cervix, there was a decrease in collagen organization and an increase in collagen fragmentation, with a significant decrease in fibril length and diameter, although fibril bundling remained unaffected [17, 18]. This, again, fits well with our data, with those reported by other groups [19, 20], and, most importantly, with the clinical appearance. During the menstrual phase, the cervix becomes clinically softer; the cervical canal opens for the menstrual bleeding, similarly to the cervical ripening for labor. Interestingly, the clinical softening of the uterine cervix during menstruation is not based on an increase in water content (Fig. 5). This phenomenon has also been described in a non-pregnant cow model, where differences in texture of the cervix could not be explained by differences in water content [20]. In pregnant humans, in turn, cervical softening was associated with a dramatic increase in water content [3], which is consistent with the findings in the cow model during pregnancy and labor [21]. Apparently, cervical softening during menstrual bleeding has a different physiology and biochemistry than cervical softening for labor. While cervical softening during menstrual bleeding seems to be based mainly on the withdrawal of sex steroids, leading to a disinhibition of metalloproteinases and disintegration of collagen, cervical ripening for labor seems to be based on inflammatory processes, with hyperemia and edema.

It is surprising that there was no difference between the data of the postmenopausal women and those of the premenopausal women. Apparently, postmenopausal atrophy of the cervical components does not affect their optical properties and the physiologic parameters derived from them.

In this study we demonstrated that withdrawal of sex hormones during menstrual bleeding is associated with a significant decrease in $\mathrm{HHb}$ and scattering power, with stable values of $\mathrm{O}_{2} \mathrm{Hb}, \mathrm{tHb}, \mathrm{StO}_{2}$, and $\mathrm{H}_{2} \mathrm{O}$ compared with the values during the follicular, luteal or postmenopausal phases of the menstrual cycle. Cervical softening during menstrual bleeding seems to be different from cervical softening for labor.

\section{References}

1. Goldenberg RL, Hauth JC, Andrews WW (2000) Intrauterine infection and preterm delivery. N Engl J Med 342:1500-1507. doi:10.1056/NEJM200005183422007

2. Leppert PC (1995) Anatomy and physiology of cervical ripening. Clin Obstet Gynecol 38:267-279. doi:10.1097/00003081199506000-00009 
3. Banos A, Wolf M, Grawe C, Stahel M, Haensse D, Fink D et al (2007) Frequency domain near-infrared spectroscopy of the uterine cervix during cervical ripening. Lasers Surg Med 39:641-646. doi:10.1002/lsm.20542

4. Bienkiewicz A, Welfel J, Kus E (1996) The influence of estrogens, progesterone and their antagonists on the collagen content in the pregnant rat uterus. Horm Metab Res 28:592-594

5. Patterson M, Pogue B, Wilson B (1993) Part 4. In: Müller GBC, Alfano R, Arridge S Beuthan J, Gratton E, Kaschke M et al (eds) Medical optical tomography: functional imaging and monitoring. Volume IS11. Society of Photo-Optical Instrumentation Engineers, Washington, p 513

6. Cope M (1991) The development of a near infrared spectroscopy system and its application for non invasive monitoring of cerebral blood and tissue oxygenation in the newborn infant. $\mathrm{PhD}$ thesis

7. Tromberg B, Coquoz O, Fishkin J, Anderson E, Pham D, Brenner $M$ et al (1996) Frequency-domain photon migration (FDPM) measurements of normal and malignant cell and tissue optical properties. Biomed Opt Spectrosc Diagnostics 3:111-116

8. Tromberg BJ, Svaasand LO, Fehr MK, Madsen SJ, Wyss P, Sansone B et al (1996) A mathematical model for light dosimetry in photodynamic destruction of human endometrium. Phys Med Biol 41:223-237. doi:10.1088/0031-9155/41/2/002

9. Garfield RE, Maner WL, MacKay LB, Schlembach D, Saade GR (2005) Comparing uterine electromyography activity of antepartum patients versus term labor patients. Am J Obstet Gynecol 193:23-29. doi:10.1016/j.ajog.2005.01.050

10. Hornung R, Pham TH, Keefe KA, Berns MW, Tadir Y, Tromberg BJ (1999) Quantitative near-infrared spectroscopy of cervical dysplasia in vivo. Hum Reprod 14:2908-2916. doi:10.1093/humrep/14.11. 2908

11. Ludmir J, Sehdev HM (2000) Anatomy and physiology of the uterine cervix. Clin Obstet Gynecol 43:433-439. doi:10.1097/ 00003081-200009000-00003

12. Li A, Felix JC, Hao J, Minoo P, Jain JK (2005) Menstrual-like breakdown and apoptosis in human endometrial explants. Hum Reprod 20:1709-1719. doi:10.1093/humrep/deh824
13. Brasted M, White CA, Kennedy TG, Salamonsen LA (2003) Mimicking the events of menstruation in the murine uterus. Biol Reprod 69:1273-1280. doi:10.1095/biolreprod.103.016550

14. Wood GA, Fata JE, Watson KL, Khokha R (2007) Circulating hormones and estrous stage predict cellular and stromal remodeling in murine uterus. Reproduction 133:1035-1044. doi:10.1530/ REP-06-0302

15. Sato T, Ito A, Mori Y, Yamashita K, Hayakawa T, Nagase $H$ (1991) Hormonal regulation of collagenolysis in uterine cervical fibroblasts. Modulation of synthesis of procollagenase, prostromelysin and tissue inhibitor of metalloproteinases (TIMP) by progesterone and oestradiol-17 beta. Biochem J 275:645-650

16. Jeffrey JJ, Roswit WT, Ehlich LS (1990) Regulation of collagenase production by steroids in uterine smooth muscle cells: an enzymatic and immunologic study. J Cell Physiol 143:396-403. doi: $10.1002 /$ jcp. 1041430226

17. Clark K, Ji H, Feltovich H, Janowski J, Carroll C, Chien EK (2006) Mifepristone-induced cervical ripening: structural, biomechanical, and molecular events. Am J Obstet Gynecol 194:13911398. doi:10.1016/j.ajog.2005.11.026

18. Rumpel E, Michna H, Kuhnel W (1993) Morphology of the rat uterus after long-term treatment with progesterone antagonists. Ann Anat 175:141-149

19. Shynlova O, Mitchell JA, Tsampalieros A, Langille BL, Lye SJ (2004) Progesterone and gravidity differentially regulate expression of extracellular matrix components in the pregnant rat myometrium. Biol Reprod 70:986-992. doi:10.1095/biolreprod.103.023648

20. Breeveld-Dwarkasing VN, de Boer-Brouwer M, te Koppele JM, Bank RA, van der Weijden GC, Taverne MA et al (2003) Regional differences in water content, collagen content, and collagen degradation in the cervix of nonpregnant cows. Biol Reprod 69:1600-1607. doi:10.1095/biolreprod.102.012443

21. Breeveld-Dwarkasing VN, te Koppele JM, Bank RA, van der Weijden GC, Taverne MA, van Dissel-Emiliani FM (2003) Changes in water content, collagen degradation, collagen content, and concentration in repeated biopsies of the cervix of pregnant cows. Biol Reprod 69:1608-1614. doi:10.1095/biolreprod.102.012534 